\title{
Editorial: Intelligent manufacturing: bridging two centuries
}

\author{
Andrew Kusiak ${ }^{1}$
}

Published online: 4 December 2018

๑) Springer Science+Business Media, LLC, part of Springer Nature 2018

The Journal of Intelligent Manufacturing was established 30 years ago with four issues published in 1990. The number of issues has gradually increased to eight per year. The journal was designed to implement a vision of symbiotic relationship between artificial intelligence and manufacturing. Back in the 1980th, I realized that artificial intelligence will have a meaningful impact on manufacturing. The fact that robots then begun to be equipped with sensors (e.g., allowing to respond to simple voice commands) have resonated well with the notion of manufacturing becoming intelligent. Though initially the role of data in manufacturing was not apparent, knowledge-based systems offered a taste of autonomy in decision-making. The emergence of data science has offered a great addition to the soft side of manufacturing. Experts begun applying machine-learning algorithms to generate models and knowledge rather than serve as a source of knowledge captured in rule-based systems. The models derived from data could be tested and their accuracy controlled by the data.

The century and a half that followed the industrial revolution has been marked with the evolution of manufacturing. Modern era manufacturing has its roots in the past half century. The progress in computer and manufacturing technology has advanced automation. Nowadays, machines are controlled by software systems rather than run by human operators. Materials and components are moved by autonomous material handling systems and stored in automated storage and retrieval systems. Drones on the verge of entering supply chains. Machine learning is making a remarkable impact on decision-making. New algorithms (e.g., deep learning, extreme learning) are researched in support of big-data applications. Depending on the scope and degree of automation and integration of manufacturing processes, different names have been used in the past three decades to describe manufacturing, ranging from flexible cells and flexible manufacturing systems to computerintegrated and intelligent manufacturing. The last term was

\footnotetext{
Andrew Kusiak

andrew-kusiak@uiowa.edu

1 The University of Iowa, Iowa City, IA, USA
}

coined around 1990 and marked with the establishment of this journal and publication of the textbook, Intelligent Manufacturing Systems (Kusiak 1990). In 1995, the Intelligent Manufacturing System (IMS) Program was launched in Japan. Back then, it was realized that the industry of one country alone could not reshape all aspects of manufacturing, rather a coordinated effort of industrialized countries was needed. Major industrial corporations from Japan, United States, Korea, and Europe have initiated collaborative efforts shaping modern manufacturing, with Japan contributing the largest number of actively-participating industries. In the United States, with a strong industrial presence of Japanese companies, the IMS research activities have centered in the Next Generation Manufacturing Systems Program, which was established as a non-profit entity. In later years, the Intelligent Manufacturing Program was expanded, with the European Union establishing its own research program in intelligent manufacturing.

The recent years have witnessed a renaissance of manufacturing. Corporations, regions, and countries explore different ideas promoting manufacturing. There is a propensity of manufacturing initiatives varying in the scope and impact. Various names have been attached to these initiatives, including Industry 4.0, the Factory of the Future, Made in China 2015, digital manufacturing, intelligent manufacturing, and smart manufacturing. These undertakings may have different priorities, however, all subscribe to the same goal of transforming manufacturing by utilizing the best technologies. The diversity of these technologies has no precedence in the history, and therefore the anticipated benefits may exceed those versed in traditional thinking.

My own vision of modern manufacturing has been outlined in the book (Kusiak 1990) and the two recent articles (Kusiak 2017, 2018). What has changed in the last three decades is the technology. The intent of three decades ago and that of today remain essentially the same-making manufacturing better. If I were to name five keywords that will resonate explicitly or implicitly in the manufacturing of the future they would be: digital manufacturing, data-science solutions, predictive engineering, sustainability, and democratization of manufacturing. It could be that searching digital 
libraries on these keywords in the future will unravel details of the greatest manufacturing transformation that will in turn offer equally impactful societal benefits.

The 2200 articles published over the three decades have amassed a tremendous intellectual store that has absorbed a large administrative effort, as well as service by the community of authors, reviewers, editors, and publishing staff. The hope is that the journal content has inspired even greater ideas and applications. No words in the language of this journal exist to express the gratitude owned by the journal and myself to these communities. Thank you all.

\section{References}

Kusiak, A. (1990). Intelligent manufacturing systems. Englewood Cliffs, NJ: Prentice Hall (published also in Chinese by Tsinghua University Publishing House, Beijing, China, 1993).

Kusiak, A. (2017). Smart manufacturing must embrace big data. Nature, 544(7648), 23-25.

Kusiak, A. (2018). Smart manufacturing. International Journal of Production Research, 56(1-2), 508-517. 